\title{
Rate of Shrinkage of Tendon Collagen: Heat, Entropy, and Free Energy of Activation of the Shrinkage of Untreated Tendon; Effect of Acid, Salt, Pickle, and Tannage on the Activation of Tendon Collagen
}

\author{
By Charles E. Weir
}

\begin{abstract}
From isothermal measurements of the rate of shrinkage of tendon collagen, it is concluded that shrinkage is a rate process involving a reaction of first order. The effects of tension and length of soaking before shrinkage are studied. Average values of heat, entropy, and free energy of shrinkage of untreated tendon are obtained by application of the theory of absolute reaction rates to the data. These values are found to be $141 \mathrm{kcal} / \mathrm{mole}, 349 \mathrm{cal} /$ mole deg, and $24.7 \mathrm{kcal} /$ mole at $60^{\circ} \mathrm{C}$, respectively, with standard deviations of $15 \mathrm{kcal} / \mathrm{mole}$, $43 \mathrm{cal} / \mathrm{mole} \mathrm{deg}$, and $0.6 \mathrm{kcal} / \mathrm{mole}$ at $60^{\circ} \mathrm{C}$, respectively. Measurements of shrinkage temperatures are discussed. The effects of $\mathrm{pH}$, salt, tanning, and pretannage treatments on the activation process are studied. Heat, entropy, and free energy decrease in acid and alkaline media. Salt solutions cause a decrease in heat and entropy but an increase in free energy in concentrated solutions. The effect of salt and acid in combination is complex, but in concentrated salt solutions an increase in free energy is observed. All tannages investigated, with the exception of chrome tanning, appear to reduce the entropy more than the heat, thereby increasing the free energy. Chrome tanning increases heat, entropy, and free energy markedly. An interpretation of the results is given.
\end{abstract}

\section{Introduction}

The shrinkage of leather and collagen, when heated in an aqueous medium, has been the subject of extensive investigations. The history of such studies is outlined adequately by McLaughlin and Theis [1] ${ }^{1}$ and Hobbs [2]. The measurement of shrinkage temperatures consists of heating a water bath containing the specimen and observing the temperature at which initial shrinkage occurs. The dimensions of the test specimen and the rate of heating are prescribed [3]. Theis and Schaffer [4], lacking a reliable analytical method for determining formaldehyde combined with collagen, proposed the measurement of the temperature of initial shrinkage as a measure of the degree of "leathering." Recent investigations by Bowes and coworkers [5] have

${ }_{1}^{1}$ Figures in brackets indicate the literature references at the end of this paper. shown that increased chrome content results in increased shrinkage temperature.

Theis and coworkers $[6,7,8]$ and Chater $[9,10]$ have investigated many factors that influence shrinkage temperature but, as far as can be ascertained, all investigations, with one exception, were concerned with the initial appearance of shrinkage under conditions of continually increasing temperature. The shrinkage temperature of chrometanned leather is generally found to be above $100^{\circ} \mathrm{C}$, and therefore it cannot be attained with an ordinary water bath. Chater [11], Harnly and Parker [12], and Merry [13] have published data showing that chrome-tanned leather having a shrinkage temperature exceeding $100^{\circ} \mathrm{C}$ will shrink progressively if the temperature of the bath is maintained at $100^{\circ} \mathrm{C}$ for a period of time. Chater [14] has presented evidence that the amount of shrinkage is a function of the initial temperature of the bath. Critical examination 
of the foregoing results tends to indicate that shrinkage does not occur at a fixed temperature, although shrinkage has been regarded as analogous to a phase change occurring at a fixed temperature [15].

Recent measurements at this Bureau [16] of the expansivity of leather and collagen showed that shrinkage occurred at a temperature many degrees lower than that ordinarily measured as the shrinkage temperatures of the specimens tested. These measurements proved that the apparent shrinkage is a result of anistropy of the material and that the net change results in an increase in real volume. One measurement made during shrinkage showed that the volume change approximately followed the first-order rate equation. This investigation was performed by observing specimens in thermal equilibrium with water over long periods of time. The results indicated that there was no fixed temperature that might be called the shrinkage temperature, but rather that shrinkage was a rate process occurring over a range of temperatures. In the previous investigation involving dilatometric techniques, it was not possible to determine the temperature coefficient and the related thermodynamic quantities of the rate process, and the present series of studies was initiated.

The present investigation, utilizing tendon collagen as the experimental material, shows that the shrinkage phenomenon is a rate process having an extremely high temperature coefficient, measurements being possible over a temperature interval of approximately 10 to $15 \mathrm{deg}$ C. The heat, entropy, and free energy of activation of the shrinkage process have been evaluated for untreated tendons and for tendons subjected to processes commonly used in the tannery.

\section{Apparatus and Method of Measure- ment}

The equipment required for the measurements consisted of a temperature-controlled water bath, suitable devices for suspending the specimen, and a cathetometer for measuring the length of the specimen.

The water bath was improvised from a cylindrical glass aquarium, 12 in. in diameter and 18 in. in depth. The bath was equipped with a controlled intermittent heater of 500-watt capacity, a variable continuous heater of 1,000-watt capacity, a thermoregulator of the toluene-mercury type, and an electrically driven stirrer. The thermostat was capable of maintaining any desired temperature between $30^{\circ}$ and $95^{\circ} \mathrm{C}$ to within $\pm 0.1^{\circ} \mathrm{C}$. At temperatures exceeding $65^{\circ} \mathrm{C}$, the surface of the water was covered with a layer of light mineral oil to reduce excessive evaporation.

A glass cylinder, closed at the lower end, was clamped in the bath in an upright position. The cylinder was a 500-ml graduate and was closed at the top with a two-hole stopper containing a thermometer and a glass rod. The thermometer, which was graduated to $0.2^{\circ} \mathrm{C}$, was placed to record the average temperature of the specimen during shrinkage. The specimen was bound to the glass rod by fine copper wire and was placed under tension by the addition of a weight at the lower end. The weight was made up of an "alligator" clip to which was fastened a brass weight. The weight was essential to prevent curling of the specimen during the initial stages of the shrinkage. The effect of the weight will be described later.

Measurements of length were obtained with a cathetometer graduated to $0.05 \mathrm{~mm}$. Readings were made of the heights of the wire at the top of the specimen and the jaw of the "alligator" clip where it clamped the specimen.

Test specimens consisted of kangaroo tail tendons, which were approximtely $1 \mathrm{~mm}$ in diameter. These tendons represent nearly pure collagen in a highly oriented form [17]. The tendons had been subjected to no chemical treatment. A confining sheath, which is occasionally found on some tendons, was found to restrict shrinkage and was therefore removed prior to test.

Measurements were made as follows. The graduate was filled with distilled water, and the bath was adjusted to the desired temperature. A length of tendon (approximately $10 \mathrm{~cm}$ and excluding ends of tendons, which give erratic results) was fastened to the glass rod, and the alligator clip with its appended weight was clamped to the bottom of the specimen. The assembly, consisting of rod, tendon, stopper, and thermometer, was then inserted into the graduate, and the stopper was seated securely. At the same instant a stopwatch was started. An initial reading of the position of the jaw of the "alligator" clip was made as rapidly as possible, that is, within 5 sec. This 
reading represents the position of the bottom of the specimen at zero time. The position of the top of the specimen was then recorded, and further readings were made of the position of the alligator clip until shrinkage ceased. The rate of shrinkage varies with time and temperature, and the interval between readings was varied. Numerous readings were made in the region of half-shrinkage to permit accurate interpolation of the data.

\section{Results and Discussion of Measure- ments on Untreated Tendon}

\section{Shrinkage Curve}

Routine measurements were made on specimens that had been soaked in water at $5^{\circ} \mathrm{C}$ prior to testing. The results obtained on shrinkage at $60^{\circ} \mathrm{C}$ of specimens soaked for varying periods of time are shown in figure 1 . In this figure the residual lengths in centimeters, that is, the lengths, $l$, at time, $t$, minus the fully shrunken length, $l_{\infty}$, are plotted as ordinate and the time in minutes as the abscissa. Coordinates of this nature were chosen in analogy with applications of the firstorder reaction equation. The curves illustrate the effect of varying the length of soaking period prior to shrinkage. It is observed that the dry

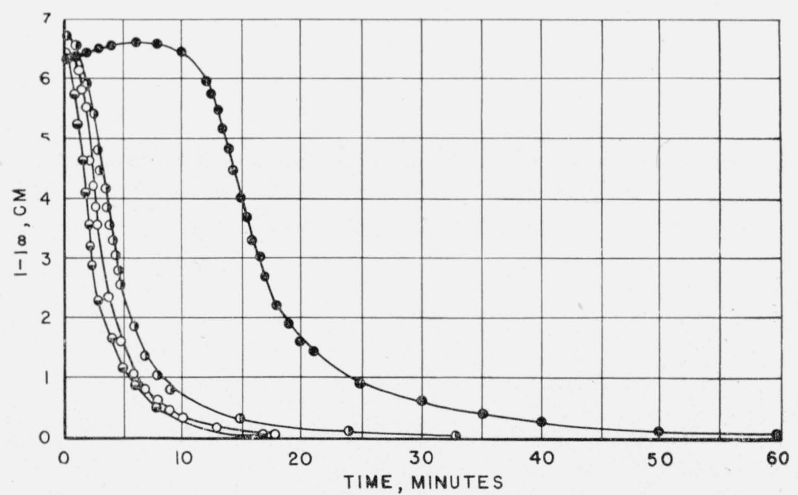

FIGURE 1. Effect of length of soaking on shrinkage.

․ Soaked $0 \mathrm{hr}$, soaked $1 \mathrm{hr}$, soaked $2 \mathrm{hr}$ : $\bigcirc$, soaked $24 \mathrm{hr}$.

specimen elongates before shrinkage occurs, probably because of absorption of water. No preliminary elongation is observed after soaking for $1 \mathrm{hr}$ or longer. Relatively little change is to be noted in either shape or position of the curve after the 1-hr soaking period. All subsequent measurements were made on tendons that were soaked in distilled water at $5^{\circ} \mathrm{C}$ for $24 \mathrm{hr}$ prior to test. This procedure was adopted for con- venience, since equilibrium appears to be attained in this period, and specimens prepared one day may be tested the following day.

In figure 2, typical shrinkage curves at various temperatures are shown. The effect of a few degrees variation in temperature is pronounced. In general, it has been found that a $2-\mathrm{deg}$ rise in temperature results in approximately a twofold increase in rate of shrinkage. This behavior differs from that of most ordinary chemical reactions in which a temperature rise of $10 \mathrm{deg} C$ approximately doubles the speed of the reaction.

The curves of figure 2 indicate that shrinkage is not a simple process. The shrinkage is seen to accelerate initially, to reach an approximately constant rate, and then to decelerate. As shown by the figure, the periods of acceleration and deceleration are shortened as the temperature increases.

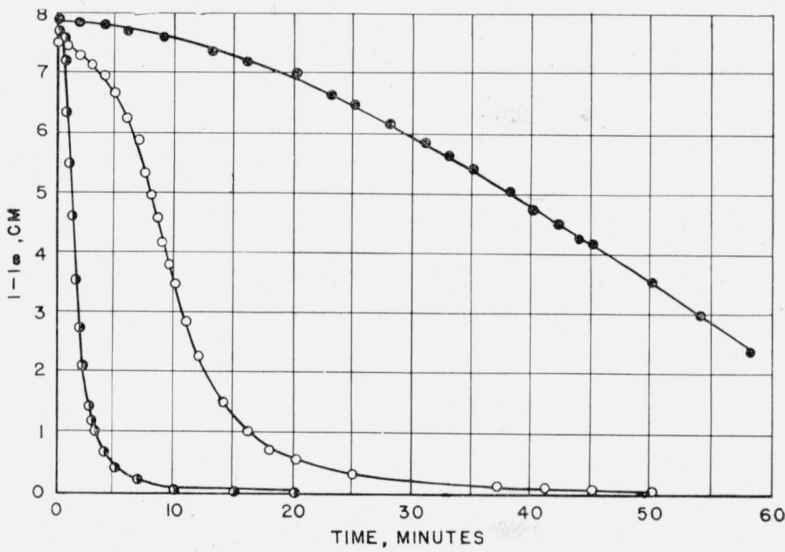

Figure 2. Effect of temperature on shrinkage.

(2) $58.4^{\circ} \mathrm{C} ; \bigcirc, 60.1^{\circ} \mathrm{C} ; 62.0^{\circ} \mathrm{C}$.

Following complete shrinkage another process occurs, which is not shown in the figure, since it is beyond the scope of this investigation. This process involves reelongation of the shrunken collagen and is presumably associated with solution of the shrunken material, weakening of the structure, and resultant stretching. This process is of concern only in that it seriously limits the range of measurements, rendering impractical any measurements requiring more than a few hours.

\section{Characteristics of Shrinkage}

The mechanism of shrinkage, as related to the structure of collagen, is of great theoretical interest but is beyond the scope of this investigation. Observations made during shrinkage may give a 
clue to the mechanism. A tendon, when first immersed with the bath at a temperature that causes a moderate rate of shrinkage, is completely quiescent. The finely corrugated regular surface of the original tendon gradually becomes slightly distorted at fixed points, the distortion being caused by tiny nodules that are formed inside the tendon. The formation of nodules marks the onset of shrinkage. A nodule grows internally, produces a large lump, and then appears to gelatinize and form a gelatinous ring around the tendon. The gelatinous ring is invariably oriented at an angle of approximately $30^{\circ}$ with the axis of the tendon and is of a much larger diameter (two to three times) than that of the tendon. Tendon adjacent to the gelatinous ring appears to be pulled into the ring from both directions. Nodules, which appear to be formed at a rate proportional to the temperature, grow, coalesce, and thus cause shrinkage. Most shrinkage is associated with nodule formation and growth, and it is most probable that the transformation of the adjacent tendon into gelatinous material is of minor importance in causing shrinkage. The drawings in figure 3 illustrate the course of the
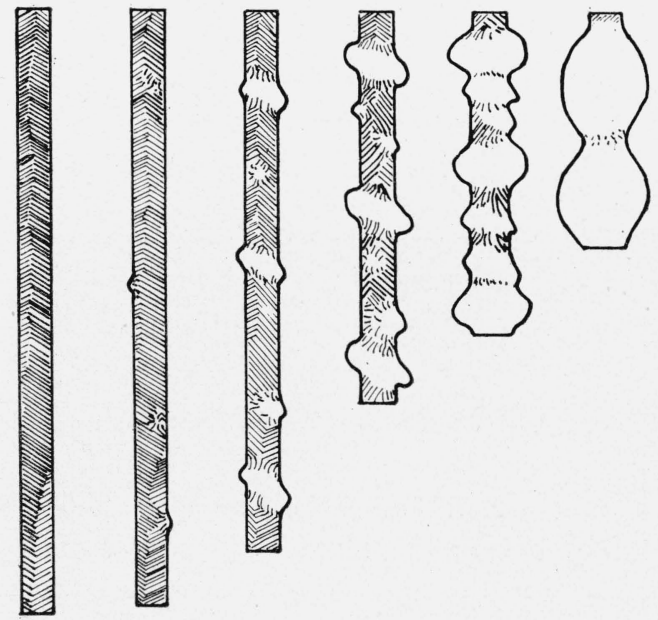

FIgURE 3. Behavior of tendon during shrinkage.

shrinkage. These observations are remarkably similar to photographs made of shrinkage of fibrils of submicroscopic dimensions by Nutting and Borasky [18].

\section{Effect of Tension on Shrinkage}

Measurements were made to determine the effect of tension on the experimental results. Shrinkage tests were made by using weights of
3.6, 14.4, and $40.2 \mathrm{~g}$. on the tendons. The results of these measurements at $65.3^{\circ} \mathrm{C}$ are shown in figure 4, measurements at other temperatures yielding comparable results. It is noted that increasing tension apparently causes decreased rate of shrinkage and an increasing induction period. This effect will be discussed subsequently.

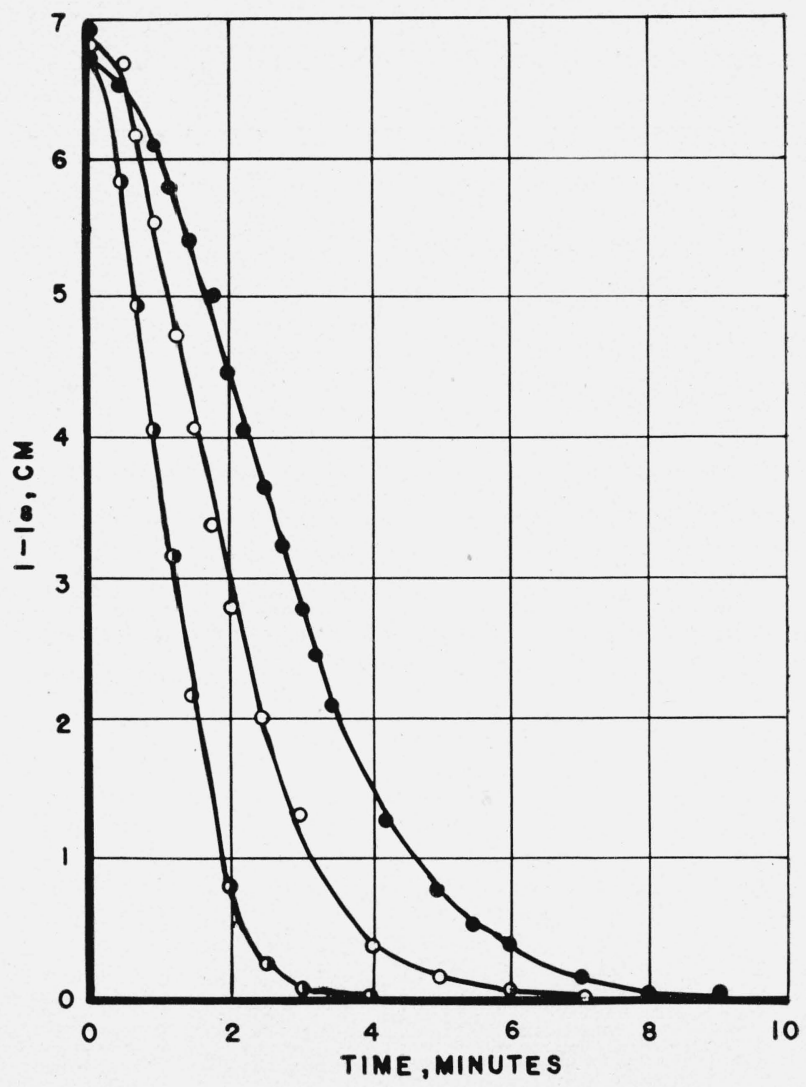

Figure 4. Effect of tension on shrinkage.

D, Load $3.6 \mathrm{~g}, 65.3^{\circ} \mathrm{C}$; $\mathrm{O}$, load $14.4 \mathrm{~g}, 65.2^{\circ} \mathrm{C}$; , load $40.2 \mathrm{~g}, 65.4^{\circ} \mathrm{C}$.

\section{Mathematical Treatment of Results}

(a) Rate Constants and Heat of Activation

The results shown in figures 1,2 , and 4 indicate that, except at low temperatures, where shrinkage is quite slow, the shrinkage follows approximately an exponential function of the time after a period of induction. Such a relationship may be written

$$
l=\left(l_{0}-l_{\infty}\right) e^{-K t}+l_{\infty},
$$

where $l$ is the length of tendon at time $t, l_{\infty}$ is the completely shrunken length, $l_{0}$ is the initial length, and $K$ is the rate constant for the shrinkage. Equation 1 is of the form of a first-order equation [19]. If such a process is investigated, a graph of $\log \left(l-l_{\infty}\right)$ as ordinate and $t$ as abscissa will yield 
reaction rates. The fundamental equation of this theory is

$$
K=\frac{k T}{h} \kappa K^{\prime}
$$

where $K$ is the reaction velocity constant, $k$, Boltzmann's constant, $h$, Planck's constant, $T$, the absolute temperature, $K^{\prime}$, the equilibrium constant of the reaction involving formation of an "activated complex," and $\kappa$, the transmission coefficient. This factor will be constant under the conditions of this experiment, and in the absence of information concerning its magnitude, will be assumed to be unity. As this reaction involves disorganization of the structure of collagen and therefore may be considered to be a decomposition, $\kappa$ probably is approximately 1 [20]. If the term in $\kappa$ is included it will represent an uncertainty in $\Delta S$ but will have no effect on $\Delta H$, as will be seen by a consideration of later equations.

Substituting for $K^{\prime}$ in eq 4 from the relationship

$$
\Delta F=-R T \ln K^{\prime}
$$

we obtain an equation relating $K$ and $F$,

$$
K=\frac{k T}{h} e^{-\Delta F / R T} .
$$

Substituting for $\Delta F$ from eq 3 ,

$$
K=\frac{k T}{h} e^{-(\Delta H / R T-\Delta S / R)} .
$$

To obtain a relationship involving $t_{1 / 2}$ in place of $K$ for reasons previously enumerated, assume the equation

$$
K=\frac{0.6932}{t_{1 / 2}}
$$

The constant 0.6932 corresponds to the numerical relationship between $K$ and $t_{1 / 2}$ for first-order reactions [19]. Substituting into eq 7 and rearranging, the following relationships are obtained:

$$
\frac{0.6932 h}{k T t_{1 / 2}}=e^{-\Delta F / R T}=e^{-(\Delta H / R T-\Delta S / R)} .
$$

By taking logarithms of these equations, it is seen that a graph of $\log 0.6932 h / k T t_{1 / 2}$ and $1 / T$ yields a line that has a slope and intercept proportioral to $\Delta H$ and $\Delta S$, respectively.
Solving eq 9 and 7 for $\Delta S$ the two following results are obtained:

$$
\Delta S=2.303 R\left[\log \frac{h}{k T}+\log \frac{1}{t_{1 / 2}}+\log 0.6932\right]+\frac{\Delta H}{T}
$$

$$
\Delta S=2.303 R\left[\log \frac{h}{k T}+\log K\right]+\frac{\Delta H}{T} .
$$

Equation 11 will yield the absolute value of $\triangle S$ for the activation. The essential difference bebetween eq 10 and 11 lies in the proportionality factor 0.6932 of eq 10. Assuming the value of 0.6932 is in error by a factor of 1,000 , an uncertainty of only $13.8 \mathrm{cal} / \mathrm{mole} \mathrm{deg}$ in $\Delta S$ results. A corresponding uncertainty of only $4.6 \mathrm{kcal} / \mathrm{mole}$ in values of $\Delta F$ at $60^{\circ} \mathrm{C}$ is obtained. Derived values of $\Delta H$ will be unaffected by uncertainties in the relationship between $K$ and $t_{1 / 2}$. It seems, therefore, that $\Delta S$ and $\Delta F$ obtained through use

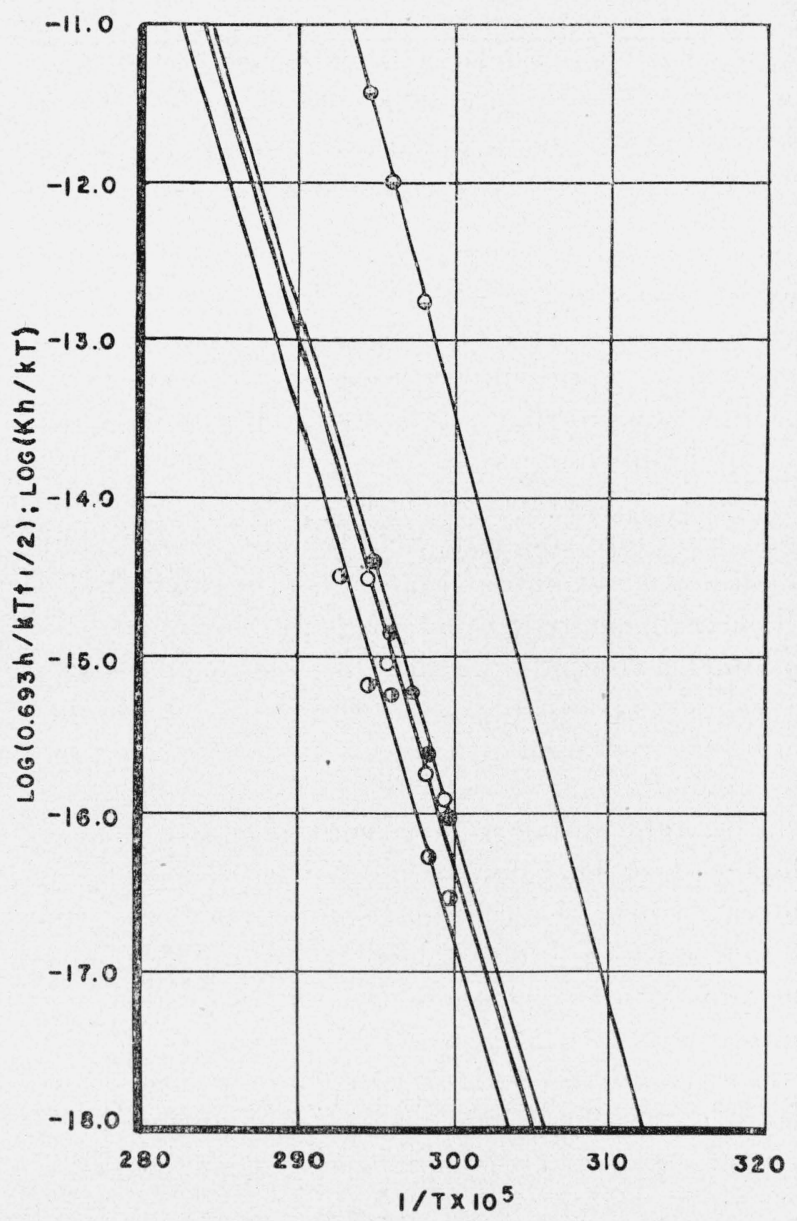

Figure 6. Application of absolute reaction rate theory to data.

ค, $14.4 \mathrm{~g}, K$ values; $3.6 \mathrm{~g}, \tau_{1 / 2}$ values; $\begin{aligned} & \text { values. } \\ & \text { valu }\end{aligned}$ 
of $t_{1 / 2}$ values may be considered to be good approximations to the absolute values of $\Delta S$ and $\Delta F$.

It will be noted that the transmission coefficient, $\kappa$, would appear in an added logarithm term in eq 10 and 11 , and unless $\kappa$ differs appreciably from unity, would have little effect on $\Delta S$.

The results obtained under three different tensions are shown in figure 6 , graphed in accordance with eq $9, \log 0.6932 h / k T t_{1 / 2}$ being plotted as ordinate and $1 / T$ as abscissa. In addition, the reaction velocity constants of the measurements with the 14.4-g weight were obtained graphically and are plotted in accordance with eq 7 . In the latter graph only three points are obtained, since no linearity and no velocity constant were obtained at the lowest temperature. The results for $\Delta H$ and $\Delta S$ shown in table 1 were obtained by application of least squares to the data shown in figure 6 and are considered to be in fair agreement. In practice it was observed that use of the largest stress greatly reduces the temperature range in which linearity may be found in a first-order application. Consequently, it is believed that the apparent deviation from the first-order reaction is in some manner related to initial stresses existing in the tendon from internal and external forces as well as to the method of measuring the course of the reaction through the change in length.

TABLE 1. Effect of tension on activation constants

\begin{tabular}{|c|c|c|c|c|}
\hline Load & $\begin{array}{l}\text { Data used } \\
\text { for } \\
\text { calculation }\end{array}$ & $\begin{array}{l}\text { Heat of acti- } \\
\text { vation, } \Delta H\end{array}$ & $\begin{array}{c}\text { Entropy of } \\
\text { activation, } \\
\Delta S\end{array}$ & $\begin{array}{c}\text { Free energy } \\
\text { of activation } \\
\text { at } 60^{\circ} \mathrm{C}, \\
\Delta F_{60}\end{array}$ \\
\hline$g$ & & $\mathrm{kcal} / \mathrm{mole}$ & $\mathrm{cal} / \mathrm{mole}$ deg & $\mathrm{kcal} / \mathrm{mole}$ \\
\hline 3.6 & $t_{1 / 2}$ & 136 & 330 & 26.2 \\
\hline 14.4 & $t_{1 / 2}$ & 136 & 334 & 24.8 \\
\hline 14.4 & $K$ & 113 & 277 & 20.8 \\
\hline 40.2 & $t_{1 / 2}$ & 154 & 385 & 25.8 \\
\hline
\end{tabular}

The results of figure 6 indicate a trend toward higher temperatures under larger tension. The increase in shrinkage temperature under tension has been reported by Wohlisch [15], but the experimental variation is such that the differences noted in figure 6 may be due to sampling.

\section{Heat, Entropy, and Free Energy of Activation of Untreated Tendons}

The results of measurements of thermodynamic activation constants of various batches of tendons in distilled water ( $\mathrm{pH} 6$ to 7 ) are shown in table 2.
Values of $\Delta H$ and $\Delta S$ were obtained by application of the least squares to data consisting of $t_{1 / 2}$ and $1 / T$ values. Values of $\Delta F_{60}$ were obtained by use of results for $\Delta H$ and $\Delta S$ and application of eq 3 and are calculated at $60^{\circ} \mathrm{C}$. This temperature was chosen since rapid shrinkage of tendons occurs at $60^{\circ} \mathrm{C}$. All measurements were made using the 14.4-g weight.

TABLE 2. Activation constants of tendon collagen

\begin{tabular}{|c|c|c|}
\hline Heat of activation, $\Delta H$ & $\begin{array}{c}\text { Entropy of } \\
\text { activation, } \\
\Delta S\end{array}$ & $\begin{array}{l}\text { Free energy of } \\
\text { activation at } \\
60^{\circ} \text { C. } \Delta F_{60}\end{array}$ \\
\hline $\mathrm{kcal} / \mathrm{mole}$ & cal/mole deg & $\mathrm{kcal} / \mathrm{mole}$ \\
\hline 136 & 334 & 25.0 \\
\hline 136 & 330 & 25.2 \\
\hline 145 & 361 & 25.1 \\
\hline 168 & 431 & 24.7 \\
\hline 152 & 383 & 24.8 \\
\hline 141 & 348 & 24.9 \\
\hline 120 & 292 & 23.2 \\
\hline 128 & 313 & 24.4 \\
\hline Average _._. & 349 & 24.7 \\
\hline Standard deviation $\ldots 15$ & 43 & 0.6 \\
\hline
\end{tabular}

It is found that, although $\Delta H$ varies between 120 to $170 \mathrm{kcal} / \mathrm{mole}$ and $\Delta S$ between 290 to 430 $\mathrm{cal} / \mathrm{mole}$ deg., the values of $\Delta F_{60}$ remain substantially constant at approximately $25 \mathrm{kcal} / \mathrm{mole}$. The size of the values of $\Delta H$ and $\Delta S$ are indicative of chemical reactions involving large molecules and agree in magnitude with similar values previously obtained for denaturation of soluble proteins [21]. The heat of activation is probably identified with rupture of bonds during activation. The entropy change is probably associated with a marked disorientation occurring in the process of activation. The variation observed in these values may be due to varying stress caused by different cross-sectional areas, as indicated by figure 6 , to varying degrees of crystallinity or bonding in different specimens, or to experimental errors inherent in determination of quantities of such magnitude.

The process of shrinkage may be assumed to be represented by the following reactions:

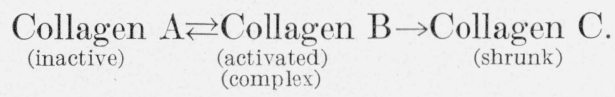

The heat, entropy, and free energies obtained relate to the equilibrium process on the left. A measure of the position of this equilibrium is given 
by $\Delta F$, as shown by eq 5 , which relates $\Delta F$ and the equilibrium constant of this process. The value of $\Delta F$ is then considered to be a measure of the temperature interval of shrinkage, as the concentration of collagen $B$ will be determined by the value of $\Delta F$ in conformity with eq 5 .

\section{Measurement of Shrinkage Temperatures}

The foregoing results show that a true shrinkage temperature does not exist, since the process involved is a rate phenomenon. The high heat of activation, however, is probably responsible for the fact that shrinkage has heretofore not been recognized as a rate process and to a large extent minimizes errors in measurements of shrinkage temperatures. However, interpretation of shrinkage as a process occurring at a fixed temperature is subject to all errors inherent in interpreting a rate phenomenon as a fixed temperature process, plus an additional serious error related to the fact that the rate of shrinkage initially accelerates from zero.

By defining the end of the acceleration period as that time at which adherence to the first-order equation begins, it has been ascertained that it has a temperature coefficient approximately equal to that of the shrinkage reaction, that is, $\Delta H \approx 130$ $\mathrm{kcal} / \mathrm{mole}$. This means that the initial process is actually a portion of the shrinkage, and it will invariably cause a shrinkage temperature measurement to yield too high a temperature, that is, a positive error.

Specimens contained in a water bath heated at the rate of $2 \mathrm{deg} \mathrm{C} / \mathrm{min}$ will necessarily remain at a temperature lower than that of the water. This consideration also leads to a positive error.

Dry specimens, when immersed in the bath require much longer periods of time before initial shrinkage than specimens that are soaked prior to test. A shrinkage test specimen placed in a bath and tested immediately may give a high result.

All experimental results indicate positive errors in measurements of shrinkage temperatures, and the results obtained from these measurements are doubtless too high [16]. For ordinary test purposes, it is believed that the present method [3] is adequate, since it is very doubtful if the error can exceed $5 \mathrm{deg}$ C. For precise work, however, the method leaves much to be desired. In such instances it should be possible to define shrinkage temperature in either one of two ways: (1) prescribe a permissible change in surface area of a specimen of known area subjected to a fixed temperature for a specified length of time, (2) define the shrinkage temperature as that temperature causing half-shrinkage in $1 \mathrm{~min}$. The first method of definition would require no apparatus other than that normally found in any laboratory. The latter, however, would necessitate rate measurements and is less preferable experimentally, although more desirable thermodynamically since it, in effect, specifies $\Delta F$ and therefore $K^{\prime}$ (eq 5).

\section{Results of Measurements on Treated Tendon}

\section{Effect of $\mathrm{pH}$ of Equilibrium Solution}

Initial attempts to evaluate thermodynamic activation constants of tanned tendons led to erratic and inexplicable results. As tanning involved occasional use of extreme $\mathrm{pH}$ values, it was decided to ascertain the effect of $\mathrm{pH}$ on the activation. In these experiments, the low $\mathrm{pH}$ values were obtained with sulfuric acid and the high $\mathrm{pH}$ values with sodium hydroxide. All specimens were allowed to equilibrate in the solution of desired $\mathrm{pH}$ for $24 \mathrm{hr}$ prior to test, and the measurements were made by using the equilibrium solution as the confining liquid. A large excess of liquid was used in every test. Extreme acid and alkaline $\mathrm{pH}$ values caused enormous swelling of the tendons, and early results showed the advisability of subjecting such specimens to refrigeration at all times prior to testing. Results of these tests are shown in table 3 and figure 7 . Table 3 shows that heat, entropy, and free energy of activation decrease in acid and alkaline solutions. Attention is called to the two latter values of the table. These values represent results obtained on tendons that had been subjected to the extreme $\mathrm{pH}$ values and then leached with water until all acid or alkali was removed. It is observed that substantial recovery of the initial state has been obtained. This result is important since it justifies the use of acid or alkali in the tanning process, provided thorough washing is effected.

The nature of the shrinkage of highly swollen tendons differs from that of normal tendons in that the acceleration period is negligible and possibly entirely missing. There is considerable 

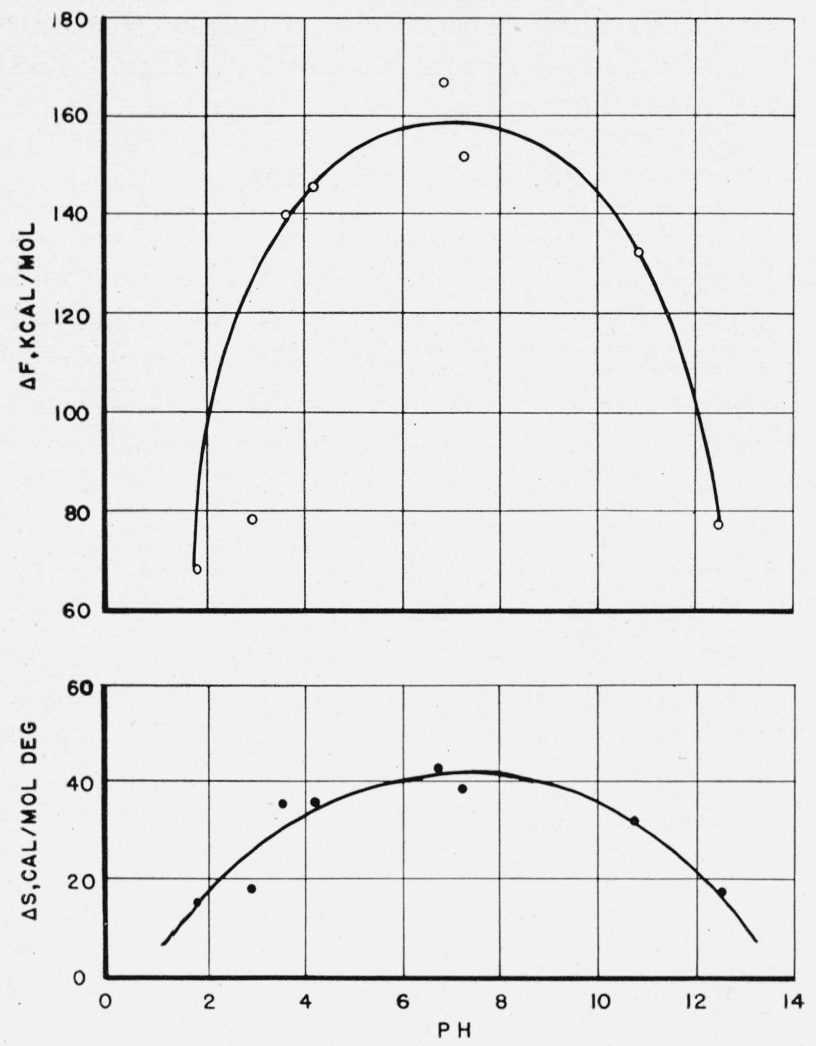

Figure 7. Effect of $\mathrm{pH}$ on heat and entropy of activation. $\mathrm{O}, \Delta \mathrm{F} ; \boldsymbol{\bullet}, \Delta \mathrm{S}$.

deviation from linearity under these conditions in the graph of $\log 0.6932 h / k T t_{1 / 2}$ versus $1 / T$ in the lower temperature ranges. It appears probable that linearity is the limiting condition occurring at high temperatures. In figure 8 the linear plots are shown from which the data of table 3 were obtained.

TABLE 3. Effect of $\mathrm{pH}$ on activation constants of tendon collagen

\begin{tabular}{|c|c|c|c|}
\hline $\mathrm{pH}$ & $\begin{array}{c}\text { Heat of } \\
\text { activation, } \\
\Delta \mathrm{H}\end{array}$ & $\begin{array}{c}\text { Entropy of } \\
\text { activation, } \\
\Delta S\end{array}$ & $\begin{array}{c}\text { Free energy } \\
\text { of activation } \\
\text { at } 60^{\circ} \mathrm{C}, \\
\Delta F_{60}\end{array}$ \\
\hline & $\mathrm{kcal} / \mathrm{mole}$ & cal/mole deg & $\mathrm{kcal} / \mathrm{mole}$ \\
\hline $\begin{array}{l}1.8 \\
3.0\end{array}$ & $\begin{array}{l}67 \\
79\end{array}$ & $\begin{array}{l}150 \\
175\end{array}$ & $\begin{array}{l}17.4 \\
20.6\end{array}$ \\
\hline $\begin{array}{l}3.0 \ldots \\
3.6 \ldots\end{array}$ & 141 & 363 & 19.8 \\
\hline 4.2 & 145 & 368 & 22.5 \\
\hline $6.8 \ldots \ldots$ & 168 & 431 & 24.7 \\
\hline $7.2 \ldots \ldots$ & 152 & 383 & 24.8 \\
\hline 10.8 & 132 & 327 & 23.5 \\
\hline 12.5 & 77 & 177 & 18.4 \\
\hline 1.8 leached with water to 7.2 & 142 & 358 & 23.3 \\
\hline 12.5 leached with water to 7.3 & 125 & 305 & 23.0 \\
\hline
\end{tabular}

Figure 8 shows indirectly that as the $\mathrm{pH}$ varies, the range of temperatures in which measurements

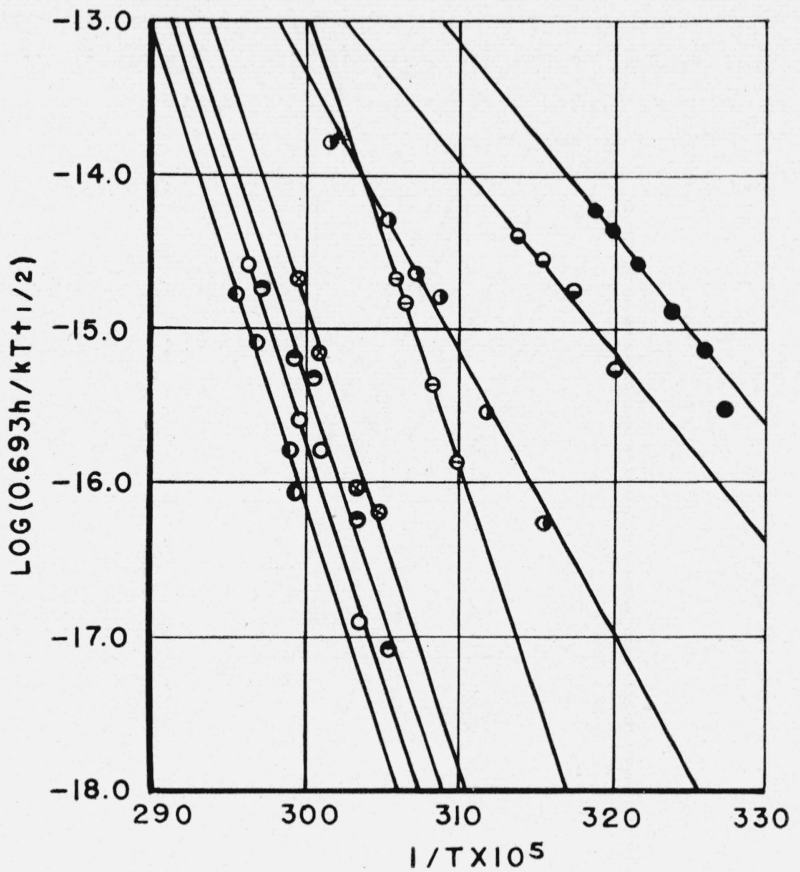

Figure 8. Effect of $\mathrm{pH}$ on rate of shrinkage.

, $\mathrm{pH} 1.8 ; \boldsymbol{O}, \mathrm{pH} 3.0 ; \ominus, \mathrm{pH} 3.6 ; \otimes, \mathrm{pH} 4.2 ; \bigcirc, \mathrm{pH} 6.8 ; \bullet, \mathrm{pH} 7.2 ; \bullet, \mathrm{pH}$ $10.8 ; \ominus, \mathrm{pH} 12.5$

can be made, that is, the shrinkage "temperature" hereafter denoted as $T_{s}$ and defined as that temperature causing half-shrinkage in 1 minute, varies in direct proportion to $\Delta F_{60}$. The variation of $T_{s}$ with $\mathrm{pH}$ is shown by the shift of the linear plots parallel to the $1 / T$ axis. This finding is in agreement with observations made by Theis [6].

The dependence of the activation constants on $\mathrm{pH}$ implies that activation involves reaction with or loss of hydrogen ions [20]. The neglect of the role of $\mathrm{H}^{+}$, implicit in application of the absolute reaction rate theory without considering the reaction of $\mathrm{H}^{+}$, is equivalent to choice of variable standard states as regards hydrogen-ion concentration. Further measurements on the effect of $\mathrm{pH}$ on activation may be expected to yield valuable information concerning the nature of the activation process.

\section{Effect of Sodium Chloride}

Since salt is widely used in the tanning process as a swelling deterrent, it is of interest to ascertain the effect of salt on the activation constants. In these tests the $\mathrm{pH}$ was maintained at approximately 6.2 , adjustments being made with dilute sulfuric acid when necessary. Solutions were made by weighing the desired quantity of chemically pure sodium chloride $(\mathrm{NaCl})$. Tendons 
were soaked in the solutions for $24 \mathrm{hr}$ prior to test and tested with the equilibrium solution as the confining liquid. Results of these tests are shown in table 4 and figure 9 .

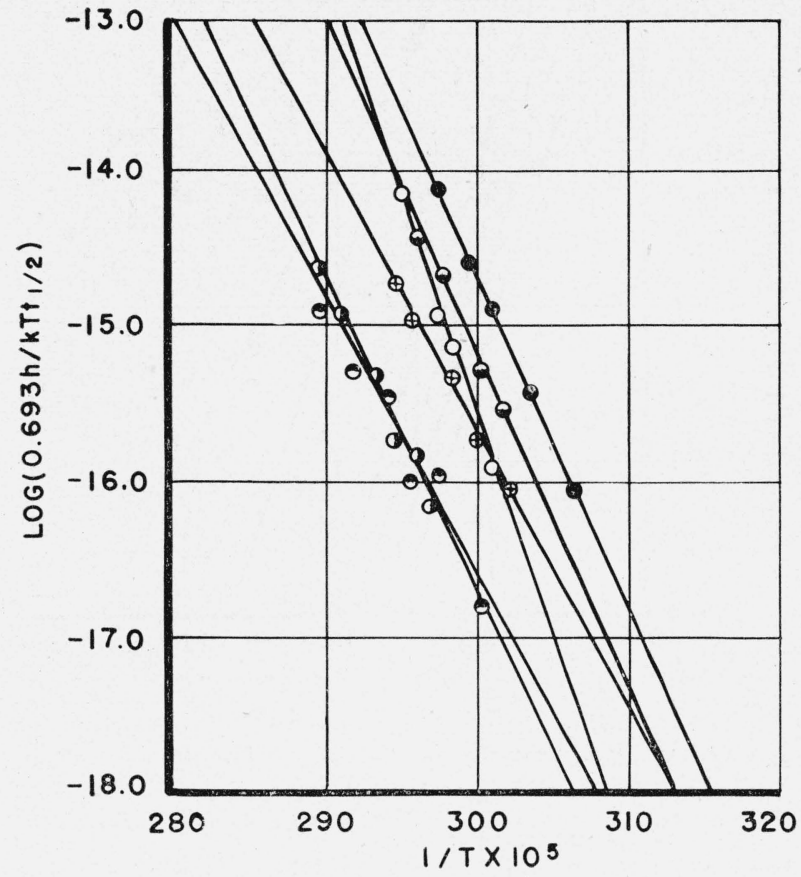

Figure 9. Effect of sodium chloride on rate of shrinkage, $\mathrm{pH}$ 6.3.

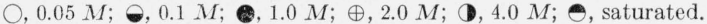

TABLE 4. Effect of sodium chloride on activation of tendon collagen

\begin{tabular}{|c|c|c|c|c|}
\hline $\begin{array}{l}\text { Concentration of } \\
\text { sodium chloride }\end{array}$ & $\begin{array}{l}\text { Acidity, } \\
\mathrm{pH}\end{array}$ & $\begin{array}{c}\text { Heat of } \\
\text { activa- } \\
\text { tion, } \Delta H\end{array}$ & $\begin{array}{c}\text { Entropy of } \\
\text { activation, } \\
\Delta S\end{array}$ & $\begin{array}{c}\text { Free energy } \\
\text { of activation } \\
\text { at } 60^{\circ} \mathrm{C}, \\
\Delta F_{60}\end{array}$ \\
\hline mole/liter & & $\mathrm{kcal} / \mathrm{mole}$ & $\mathrm{cal} / \mathrm{mole}$ deg & $\mathrm{kcal} /$ mole \\
\hline $0.00 \ldots$ & 6.0 & 141 & 349 & 24.7 \\
\hline .05 & 6.3 & 119 & 285 & 23. \\
\hline $.1 \ldots$ & 6.2 & 95 & 217 & 23 \\
\hline $1.0 \ldots$ & 6.3 & 93 & 213 & 22. \\
\hline $2.0 \ldots$ & 6.2 & 83 & 176 & 24.1 \\
\hline $4.0 \ldots$ & 6.1 & 87 & 185 & 25. \\
\hline Saturated.... & 6.0 & 75 & 149 & 25.3 \\
\hline
\end{tabular}

It is observed in table 4 that $\Delta H$ and $\Delta S$ decrease with increased concentration of sodium chloride with one exception, that is, $4 M$ sodium chloride. This exception, however, lies well within the limits of variation noted for untreated tendon. The value of $\Delta F_{60}$ remains substantially constant but appears to proceed through a minimum in the region of $1 M$ sodium chloride. The variation of $\Delta F_{60}$ is beyond the experimental variation and is probably real. In figure 9 it is noted that $T_{s}$ likewise reaches a minimum in this region of concentration of sodium chloride. This result corroborates findings by Theis [6].

\section{Effect of Pickling}

The effect of a combination of acid and sodium chloride was determined in a similar manner. One concentration of acid was used, and the salt content was varied. Sulfuric acid of $\mathrm{pH} 1.8$ was used because of the low activation constants observed at this $\mathrm{pH}$ and the fact that maximum swelling of collagen occurs in this region of $\mathrm{pH}$, as shown by Highberger [22]. Tendons were soaked in the solutions for $24 \mathrm{hr}$ and tested using the equilibrium solution as the confining liquid. Desired concentrations of sodium chloride were obtained by weighing chemically pure $\mathrm{NaCl}$. The results of these tests are given in table 5 and figure 10 .

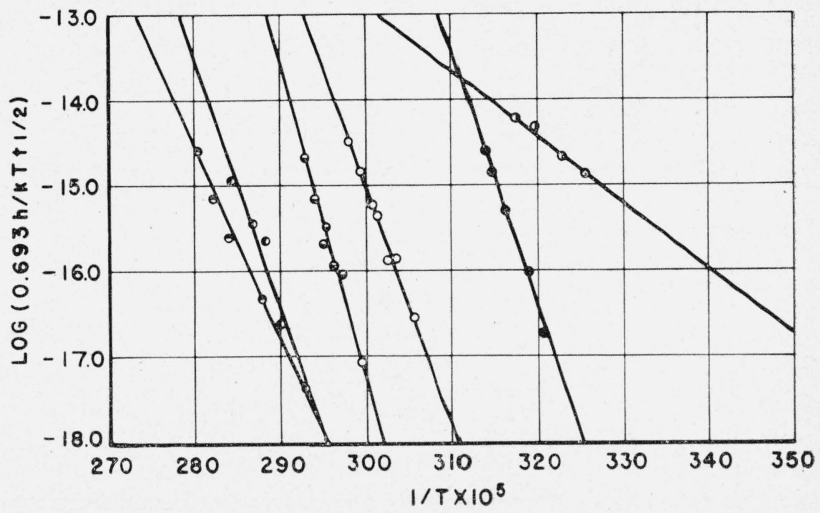

FIG URE 10. Effect of sodium chloride on rate of shrinkage, $\mathrm{pH} 1.8$.

๑, $0.1 \mathrm{M} ; 0.5 \mathrm{M} ; \bigcirc, 1.0 \mathrm{M} ; \bullet, 2.0 \mathrm{M} ; 0,4.0 \mathrm{M}$; , saturated.

TABLE 5. Effect of acid and salt on activation constants of tendon collagen

\begin{tabular}{|c|c|c|c|c|}
\hline $\begin{array}{l}\text { Concentration of } \\
\text { sodium chloride }\end{array}$ & $\begin{array}{l}\text { Acidity } \\
\mathrm{pH}\end{array}$ & $\begin{array}{c}\text { Heat of } \\
\text { activation, } \\
\Delta H\end{array}$ & $\begin{array}{c}\text { Entropy of } \\
\text { activation, } \\
\Delta S\end{array}$ & $\begin{array}{l}\text { Free energy } \\
\text { of activation } \\
\text { at } 60^{\circ} \mathrm{C}, \Delta F_{60}\end{array}$ \\
\hline Mole/liter & 1.8 & $\begin{array}{r}\mathrm{kcal} / \mathrm{mole} \\
67.0\end{array}$ & $\begin{array}{c}\mathrm{cal} / \mathrm{mole} \text { deg } \\
150\end{array}$ & $\begin{array}{r}\mathrm{kcal} / \mathrm{mole} \\
17.4\end{array}$ \\
\hline $.1 \ldots$ & 1.8 & 31.2 & 56.2 & 12.4 \\
\hline $.5 \ldots$ & 1.8 & 139 & 369 & 16.3 \\
\hline $1.0 \ldots \ldots$ & 1.8 & 126 & 310 & 23.3 \\
\hline $2.0 \ldots$ & 1.7 & 161 & 405 & 26. 2 \\
\hline 4. 0 & 1.8 & 133 & 324 & 29.9 \\
\hline Saturated ............ & 1.8 & 109 & 212 & 29.1 \\
\hline
\end{tabular}

It is of interest to compare these values with the results previously obtained with sulfuric acid and sodium chloride individually. Bearing in mind the experimental variation previously obtained with 
untreated tendons, the general trends with increasing concentration of sodium chloride appear to be as follows: (1) $\Delta H$ increases, passes through a maximum, and then decreases, (2) $\Delta S$ follows a similar behavior, (3) $\Delta F_{60}$ appears to increase monotonically. Comparing these results with those obtained previously, it is seen that the behavior of the combination of sodium chloride plus sulfuric acid toward collagen is not a simple additive property of the individual effects. The results indicate that pickling is complex in nature and possibly involves two competitive reactions involving collagen, sulfuric acid, and sodium chloride.

It is known that acid and salt individually cause swelling of collagen $[22,23]$. It was observed that the swelling caused by $0.1 M$ sodium chloride in sulfuric acid of $\mathrm{pH} 1.8$ was far greater than that resulting from sulfuric acid of $\mathrm{pH} 1.8$ alone. This is probably the cause of the low constants found for the $0.1 \mathrm{M}$ sodium chloride solution of $\mathrm{pH} 1.8$.

\section{Effect of Tanning}

Tanning of the tendons has presented difficulties, particularly in view of the fact that extraneous masking salts are undesirable because they may introduce unknown effects. Tanning was effected in most instances by immersing the specimens in a solution of the tanning agent and adjusting the $\mathrm{pH}$ to the optimum value. Following tannage, specimens were thoroughly washed and tested by using distilled water as the confining liquid. Some specimens were reserved for analysis, consisting in most instances of an ash determination. Tannage with iron and aluminum was found to necessitate masking salts and, to date, no satisfactory vegetabletanned tendons have been prepared. This does not imply that vegetable tannage does not occur, but for purposes of test a uniform tannage must be obtained, and the uniformity presents difficulties.

Tannages were secured by the following methods: formaldehyde: 15-percent solution of formaldehyde, $\mathrm{pH} 6$ to 7 [24]. Vanadium: saturated solution of sodium vanadate, $\mathrm{pH} 3$ [25]. Iron: solution of ferric sulfate and citric acid, $\mathrm{pH} 5$ [26]. Aluminum: solution of aluminum sulfate and sodium citrate, $\mathrm{pH} 5$ [27]. Uranium: solution of sodium uranate (complex carbonate formed), $\mathrm{pH} 5$ [28]. Zirconium: solution of zirconyl sulfate, $\mathrm{pH} 2$ [29]. Chromium: two-bath process consisting of immersion in a solution of potassium dichromate followed by reduction with a solution of sodium bisulfite [1]. Bating: trypsin treatment in saturated solution of calcium carbonate at $35^{\circ} \mathrm{C}$ for $24 \mathrm{hr}$.

The results of tests of tendons subjected to these tannages and treatments are given in table 6 .

TABLE 6. Effect of tanning and pretannage treatments on activation constants of tendon collagen

\begin{tabular}{|c|c|c|c|c|}
\hline Tannage or treatment & $\begin{array}{c}\text { Ash (dry } \\
\text { basis) }\end{array}$ & $\begin{array}{c}\text { Heat of } \\
\text { activation, } \\
\Delta \mathrm{S}\end{array}$ & $\begin{array}{c}\text { Entropy of } \\
\text { activation, } \\
\qquad \mathrm{S}\end{array}$ & $\begin{array}{l}\text { Free energy } \\
\text { of activation } \\
\text { at } 60^{\circ} \mathrm{C} \cdot \Delta \mathrm{F}_{60}\end{array}$ \\
\hline & Percent & $\mathrm{kcal} / \mathrm{mole}$ & cal/mole deg & $\mathrm{kcal} / \mathrm{mole}$ \\
\hline Bated. & $\ldots$ & 161 & 408 & 24.8 \\
\hline Thiosulfate .... & $\ldots$ & 131 & 318 & 24.6 \\
\hline Bisulfite ........ & $\ldots$ & 164 & 421 & 23.7 \\
\hline Dichromate & $\ldots$ & 129 & 286 & 23.7 \\
\hline Formaldehyde ....... & . & 113 & 252 & 29.0 \\
\hline Zirconium & 27.0 & 137 & 307 & 35.1 \\
\hline Iron ........... & 5.3 & 119 & 282 & 25.4 \\
\hline Vanadium ...... & 12.3 & 118 & 281 & 25.2 \\
\hline Aluminum & 1.5 & 82.1 & 172 & 24.8 \\
\hline Uranium ..... & 3.0 & 102 & 231 & 25.3 \\
\hline Chromium... & $0.06\left(\mathrm{Cr}_{2} \mathrm{O}_{3}\right)$ & 160 & 404 & 26.5 \\
\hline Do & $.13\left(\mathrm{Cr}_{2} \mathrm{O}_{3}\right)$ & 203 & 522 & 28.5 \\
\hline Do & $.57\left(\mathrm{Cr}_{2} \mathrm{O}_{3}\right)$ & 323 & 862 & 36.1 \\
\hline Do & $1.02\left(\mathrm{Cr}_{2} \mathrm{O}_{3}\right)$ & 390 & 1,041 & 44. 1 \\
\hline Do & 1. $98\left(\mathrm{Cr}_{2} \mathrm{O}_{3}\right)$ & 325 & 841 & 45.2 \\
\hline
\end{tabular}

Three important conclusions are to be drawn from the results of table 6 as follows: (1) Chrome tanning alone drastically increases $\Delta H, \Delta S$, and $\Delta F_{60}$. Further, the amount of chrome required to produce this effect is small, that is, about 0.6 percent of chromium oxide $\left(\mathrm{Cr}_{2} \mathrm{O}_{3}\right)$. (Chromium contents were determined by perchloric acid and by colorimetric methods $[3,30])$. (2) Tanning with zirconium and treating with sodium dichromate, sodium bisulfite, sodium thiosulfate, and trypsin have no appreciable effect on $\Delta H$, and, of these, zirconium alone increases $\Delta F_{60}$, an increase resulting by decrease of $\Delta S$. (3) Tanning with formaldehyde, vanadium, iron, aluminum, and uranium appears to decrease $\Delta H$ but, except for formaldehyde, does not affect $\Delta F_{60}$ appreciably. In some instances the decrease in $\Delta H$ is doubtful since it is small.

Tanning with most metallic tanning agents increased the ash content only slightly, and in most instances probably mediocre tannage was obtained. However, in view of the extraordinary changes caused by 0.6 percent of $\mathrm{Cr}_{2} \mathrm{O}_{3}$, it is seen that other metallic tans differ from chromium.

The graphical results from which $\Delta H$ and $\Delta S$ 


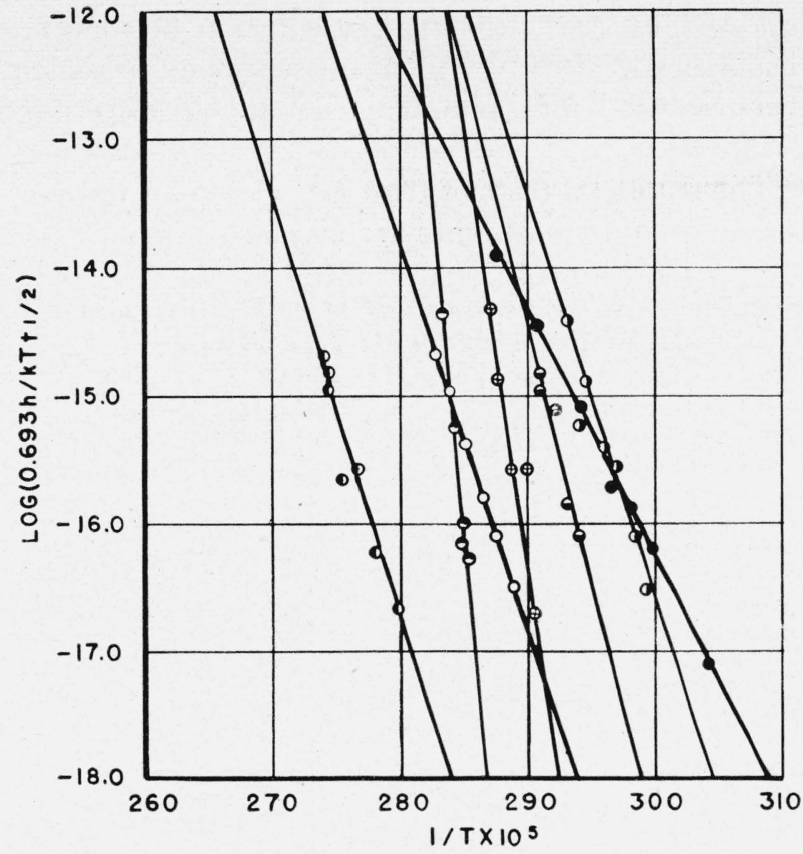

Figure 11. Effect of tannage on rate of shrinkage.

-. Alum tanned; $($, iron tanned; $\boldsymbol{O}$, zirconium tanned; $\bigcirc$, formaldehyde tanned; $\Theta$, chrome tanned, 0.13 percent $\mathrm{CR}_{2} \mathrm{O}_{3} ; \oplus$, chrome tanned, 0.57 percent $\mathrm{CR}_{2} \mathrm{O}_{3} ; \odot$, chrome tanned, 1.03 percent $\mathrm{CR}_{2} \mathrm{O}_{3}$.

were determined are shown for some tannages in figure 11 .

\section{Discussion}

\section{Hydrothermal Stability of Leather and Collagen}

Shrinkage is a rate process and, as such, presumably proceeds at all temperatures at a rate governed by the temperature, previous treatment, and environment as shown by the foregoing results. To obtain an idea of the behavior at room temperature a graph was made in which the logarithm of the time of half shrinkage in minutes, $\log t_{1 / 2}$, is plotted as ordinate and the reciprocal of the absolute temperature, $1 / T$, as abscissa. The measurements are limited to a short temperature interval by virtue of the large value of $\Delta H$ but, assuming the linearity is valid beyond this range, it is possible to extrapolate to room temperature and obtain the time of half shrinkage at such temperature. The graphs are shown in figure 12 . Because of the nature of the slopes and intercepts, it is not possible to show all extrapolated curves on the same graph, but the extrapolations of all results shown in figure 12 yield the approximate values of $t_{1 / 2}$ at $25^{\circ} \mathrm{C}$ shown in table 7 .

The results of table 7 must be considered approximations if only because of the length of the

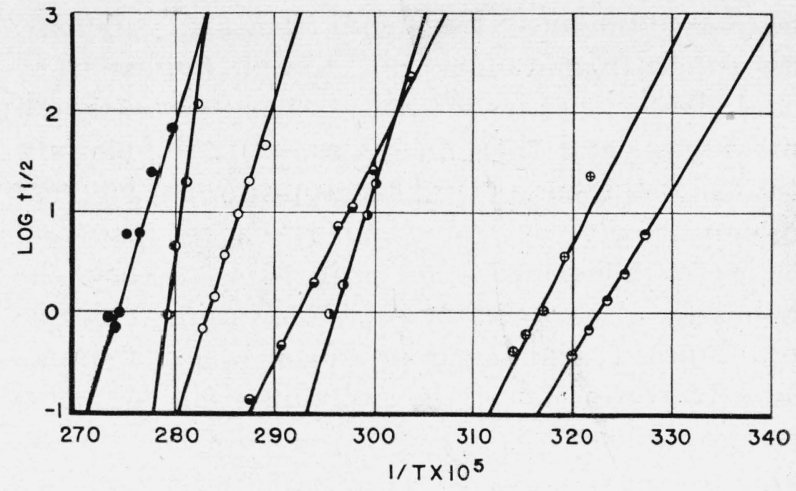

Figure 12. Effect of tannage on half-shrinkage time.

- Zirconium tanned; $\bigcirc$, formaldehyde tanned; $\mathbf{O}$, chrome tanned; ๑, alum tanned; $\mathbf{D}$, untreated, $\mathrm{pH} 7.2 ; \oplus$, sulfuric acid, $\mathrm{pH} 1.8 ; \boldsymbol{\odot}$, sodium hydroxide, $\mathrm{pH} 12.4$.

necessary extrapolation, but, even as approximations, interesting conclusions result. It is noted that extreme $\mathrm{pH}$ values cause fairly rapid shrinkage, that is, small time of half-shrinkage. It is for this reason that specimens in alkaline and acid solutions were cooled as previously described. Tanning, with the exception of alum-tanning, drastically increases the time of half-shrinkage at room temperature. This increase is due to two factors: (1) A shift of the line to lower values of $1 / T$, that is, increased $T_{s}$, and (2) an increase in the slope of the line, that is, increase in $\Delta H$. This latter behavior is noted only in the case of chrometanned tendon. A comparison of the relative efficiency of these two processes in increasing $t_{1 / 2}$ is afforded by comparing the values of $t_{1 / 2}$ for chrome and zirconium tannages. The zirconium tannage caused the largest shift in $T_{s}$., whereas the chrome tannage increased $\Delta H$. It is noted from table 7 that the latter effect is many fold more effective in increasing $t_{1 / 2}$. To date, however, no treatment other than chrome tanning has been observed to produce an increase in $\Delta H$.

TABLE 7. Time of half-shrinkage at $25^{\circ} \mathrm{C}$

\begin{tabular}{|c|c|}
\hline \hline Treatment & $\begin{array}{c}\text { Time of half- } \\
\text { shrinkage, } t_{1 / 2}\end{array}$ \\
\cline { 1 - 2 } & $\min$ \\
Chrome-tanned & $2 \times 10^{40}$ \\
Formaldehyde-tanned & $3 \times 10^{17}$ \\
Zirconium-tanned & $5 \times 10^{20}$ \\
Alum-tanned & $8 \times 10^{9}$ \\
Untanned, pH 7.2 & $5 \times 10^{12}$ \\
Untanned, pH 1.8 & $1.5 \times 10^{2}$ \\
Untanned, pH 12.4 & $8 \times 10^{3}$ \\
& \\
\hline
\end{tabular}

Recent results obtained in this laboratory by Kanagy [31] indicate that shrinkage at slightly 
elevated temperatures and high relative humidity may be an important factor in the deterioration of leather. From this point of view, it would appear that the most stable material would result from chrome-tanned leather having the highest possible shrinkage temperature.

The results of table 7 show that the time of half-shrinkage is drastically reduced when tendons are subjected to extreme values of $\mathrm{pH}$. Assuming that hide behaves in a similar manner, it is concluded that exposure of untanned skins to extreme values of $\mathrm{pH}$ may cause irreparable damage to the finished leather, unless a swelling deterrent such as salt is present.

\section{Interpretation of Heat, Entropy, and Free Energy of Activation}

(a) General Considerations

Theories of the structure of collagen and the tanning process have been published by many authors. An excellent bibliography is given by McLaughlin and Theis [1]. Essentially, the present picture of collagen assumes three types of forces: (1) valence forces along the peptide chains, (2) salt bonds (ionic linkages) between carboxyl and amino groups occurring in side chains of acidic and basic amino acids, and (3) hydrogen bonds between carbonyl groups and neighboring amino or imino groups. The particular theory of tanning of interest here is the "bridging" theory, the origin of which is in controversy [32]. This theory depicts tanning as a reaction in which a tannin molecule reacts with portions of two adjacent peptide chains to form a "bridge." The resultant increase in shrinkage temperature is conceived as due to the increased thermostability conferred by the cross-linking tannin molecules. Shrinkage is then postulated as due to rupture of cross-linkages by thermal agitation and a subsequent collapse of the polypeptide gridwork [1]. The evidence for the rupture of linkages during shrinkage has been given by Gustavson [33] and Theis [34].

Gelatinization involves rupture of few peptide linkages [35], whereas the shrunken collagen possesses a larger number of active groups than the original material $[33,34]$. Therefore it is probable that the activation process consists of rupture of key cross-linkages in the collagen molecule. On the assumption that the same cross-linkages must be broken irrespective of the initial configuration, that is, the structure of the activated complex is essentially the same, regardless of tannage, environment, etc., it is possible to obtain interesting information from the foregoing results.

Superficially, the results show that the activation reaction (eq 12) involves absorption of a tremendous quantity of heat. The total heat absorbed in the transformation of collagen A into collagen $\mathrm{C}$ has been measured calorimetrically and is of the order of $12.5 \mathrm{cal} / \mathrm{g}$ [36]. On the assumption that no heat is involved in the irreversible process (collagen $\mathrm{B} \rightarrow$ collagen $\mathrm{C}$ ), this figure combined with the value of heat of activation $141 \mathrm{kcal} / \mathrm{mole}$ gives a molecular weight of 11,300 for collagen, a figure of the order of magnitude expected for a protein. However, the assumption involved in the calculation is most probably not valid. It appears that no further progress along these lines is possible without extensive calorimetric investigations.

The size of the heat of activation is not disturbing, since large molecules are involved in this reaction. As shown above, an assumption of a molecular weight of 11,300 yields the correct value for the heat of shrinkage. Inasmuch as the molecula may be much larger, the values of heat and entropy involved are not excessive.

\section{(b) Heat of Activation}

The linkages ruptured in activation are probably either salt or hydrogen bonds. Consider the following facts about $\Delta H$ : (1) $\Delta H$ decreases with increasing concentration of sulfuric acid (to $\mathrm{pH}$ 1.8); (2) $\Delta H$ decreases with increasing concentration of sodium chloride, even in concentrated solutions; (3) $\Delta H$ decreases with increasing concentration of sodium hydroxide (to $\mathrm{pH} 12.5$ ).

Since electrolytes may be expected to act primarily at ionic linkages and $\Delta H$ appears to decrease in acid, base, and salt solutions, the effect may be attributed to a salt-type interaction. From this consideration plus the fact that a large number of hydrogen bonds must be postulated to account for the magnitude of the $\Delta H$ value observed, it is believed that $\Delta H$ measures for the most part the strength of the salt linkages in the collagen molecule.

The results obtained may all be explained by interaction of solutes at salt bonds combined with swelling of the protein structure. However, the effects of electrolytes on hydrogen bonding might conceivably cause similar effects. In the light of 
the results obtained with sodium chloride, it is believed preferable to conclude that salt bonds rather than hydrogen bonds are primarily responsible for the variations observed in $\Delta H$, and further that salt bonds contribute at least $70 \mathrm{kcal}$ to the total $140 \mathrm{keal}$ observed for $\Delta H$.

If the bridging theory of tanning is correct, it is to be expected that $\Delta H$ will increase on tanning. Chromium is the only material investigated that causes such increase in $\Delta H$. Other tanning materials, such as iron, uranium, vanadium, and formaldehyde, appear to decrease $\Delta H$, although the variation is so small as to be doubtful in view of the experimental spread found previously. Aluminum decreases $\Delta H$ and, therefore, behaves as a salt interacting with the salt bond.

Chromium drastically increases $\Delta H$, and the increase may be pictured as due to either strengthening existing cross-linkages or formation of new linkages.

Therefore it is believed, on the basis of the present experimental evidence, that $\Delta H$ measures the salt-bond cohesion energy and that chromium alone, of the materials studied, can form any crosslinks between polypeptide chains. Highberger has presented evidence of a mechanical nature that formaldehyde does not form cross-linkages [37].

Inspection of results obtained with chrometanned tendons shows that-about 1.0 percent of chromium oxide is sufficient to produce the apparent maximum cross-linking and that further increase in chrome content produces small effect. This amount of chromium is far less than the amount required to react with the excess acidic and basic groups present in collagen [35]. Therefore, it is necessary to conclude that only a fraction of these groups present possess the required spatial orientation to either form salt-bonds, which are strengthened by chromium, or react with chromium itself to form new cross-linkages. The amount of chromium combined in excess of 1 percent probably combines with other groups of the collagen in the same manner as the other tanning materials studied, that is, affects $\Delta S$.

\section{(c) Entropy of Activation}

The entropy of activation is identified with the degree of disorganization or disorientation occurring in the activation process. This term will, in effect, measure the crystallinity of the collagen, prior to activation, assuming similar final states as regards collagen B. Thus the addition of 1 percent of chromium produces more orientation, a result in agreement with the bridging theory. Acids, bases, and salts, as well as all tanning materials, aside from chromium, in general appear to decrease the $\Delta S$ factor. This means that less orientation results under these conditions and implies reaction of collagen with these materials in a more or less random manner that may involve rupture of salt bonds, that is, decreased $\Delta H$. The results obtained with aluminum are interpreted to mean a rupture of salt bonds and a corresponding disorientation sufficient in magnitude to offset the energy lost by rupture. The free energy in this case remains unchanged. Zirconium, on the other hand, tends to react in such a manner that few salt bonds are broken (normal $\Delta H$ ). However, a loss in orientation is found to occur since $\Delta S$ is smaller than for untreated tendon, as shown by the increased value of $\Delta F_{60}$. In chrome tanning, a marked increase in $\Delta H$ occurs, but the increase in $\Delta S$ is correspondingly less, since $\Delta F_{60}$ increases. A portion of the chrome, that is, possibly the whole amount $>1$ percent of $\mathrm{Cr}_{2} \mathrm{O}_{3}$ and a portion of the initial 1 percent, can be considered to add nothing to the orientation. This means some loss of organization due to chrome tanning as well as to other types of tanning. These conclusions are borne out by observations that tanning reduces crystallinity, as shown by X-ray diffraction studies [38].

\section{(d) Free Energy of Activation}

The free energy of activation is a measure of the position of equilibrium in the activation reaction. Since shrinkage will ensue rapidly, provided sufficient numbers of activated molecules are formed, $\Delta F_{60}$ will then be a measure of the shrinkage "temperature," $T_{s} . \quad \Delta F_{T}$ will vary with temperatures by virtue of its dependence on the factor $T \Delta S$. It is found that rapid shrinkage occurs at temperatures at which $\Delta F_{T} \approx 25 \mathrm{kcal} /$ mole, that is, rapid shrinkage may take place only if the activation equilibrium has been displaced sufficiently to provide required numbers of activated molecules.

The foregoing conclusion implies that treatments that reduce $\Delta S$ or increase $\Delta H$ will increase $\Delta F_{60}$ and consequently the shrinkage "temperature." Chromium tans principally by the latter 
method, that is, increases $\Delta H$ up to 1 percent of $\mathrm{Cr}_{2} \mathrm{O}_{3}$ and by the former in amounts exceeding this percentage. All other tannages tested appear to tan by reduction of $\Delta S$. This reduction in $\Delta \mathrm{S}$ may be pictured as resulting in an increased $T_{s}$ by steric hindrance phenomena. The amount of steric hindrance may be assumed to be proportional to the tannin content-percentage of $\mathrm{Cr}_{2} \mathrm{O}_{3}$ in chrome tanning, $\mathrm{pH}$ in acid solutions, etc.

Since $T_{s}$ is determined by $\Delta F_{T}$, graphs were made using $\Delta F_{60}$ as the ordinate and logarithm of the percentage chrome as the abscissa. It was found that a linear relationship resulted. If the logarithm of the concentration of solute, $[\mathrm{NaCl}]$, or the $\mathrm{pH}$ is used as the abscissa, straight lines are also obtained. Figure 13 shows typical results obtained for such graphs.

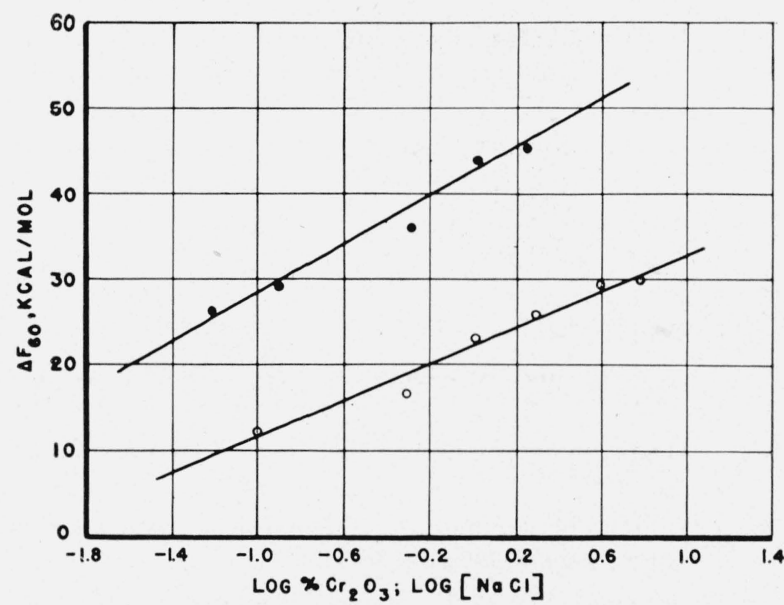

FIGURE 13. Effect of chromium oxide content and sodium chloride on free energy.

- Chrome tanned; $\bigcirc$, pickled.

$\Delta F_{T}$ is related to the equilibrium constant of the activation process, $K^{\prime}$, by the equation,

$$
\Delta F_{T}=-R T \ln K^{\prime} .
$$

The results shown in figure 13 imply that the logarithm of the equilibrium constant is linearly related to the logarithm of the chromium content, concentration of solute, etc.

Proceeding by speculation, assume $K^{\prime}=C$ $\left[\mathrm{Cr}_{2} \mathrm{O}_{3}\right]^{n}$, where $C$ and $n$ are constants. Then substituting in eq 3 , the following equation is obtained:

$$
\Delta F_{T}=-R T \ln C\left[\mathrm{Cr}_{2} \mathrm{O}_{3}\right]^{n} .
$$

In the case of rapid shrinkage it has been ascertained that $\Delta F_{T}$ is nominally constant and ap- proximately equal to $25 \mathrm{kcal} / \mathrm{mole}$ at that temperature considered to be the shrinkage "temperature." Substituting this value for $\Delta F_{T}$ and rearranging,

$$
\log \left[\mathrm{Cr}_{2} \mathrm{O}_{3}\right]=-\frac{25 \times 10^{3}}{2.303 \operatorname{Rn} T}+\frac{\log C}{n} .
$$

The concentration of $\mathrm{Cr}_{2} \mathrm{O}_{3}$ is not known, but it will be assumed proportional to the percentage of $\mathrm{Cr}_{2} \mathrm{O}_{3}$. On this basis if the logarithm of the percentage chrome is plotted against the reciprocal of the absolute temperature of shrinkage, a straight line is expected. The data presented by Bowes, et al. [5] have been tested in this manner, and a straight-line results. Bowes showed that a straight line was obtained by using the temperature instead of the reciprocal of the absolute temperature but found it necessary to mention possible negative shrinkage temperatures, which might arise. The graph, according to eq 5, eliminates the difficulties of negative shrinkage temperatures and at the same times yields a satisfactory linear plot. Inasmuch as $t$ is proportional to $1 / T$ over the limited temperature range involved, the linearity using either $t$ or $1 / T$ is not unexpected. No conclusions are possible concerning the slope of the line obtained, since the unknown factor $n$ is involved. By using the experimental value given by Bowes, it is found that the value of $n$ is approximately 1 .

No conclusions concerning the mechanism of shrinkage may be made from the present results at this time. It is believed, as a result of observations during shrinkage, that the shrinkage reaction involves water either as a reactant or a catalyst. Experiments are in progress to ascertain the role of water in the shrinkage.

The experimental results obtained in this investigation are in substantial qualitative and quantitative agreement with results of studies made on soluble proteins. Excellent summaries of these researches are given by Eyring and Stearn [39] and Neurath, et al. [21].

The author is indebted to A. A. Maryott for valuable suggestions concerning the treatment. of the data and the manuscript. 


\section{References}

[1] G. D. McLaughlin and E. R. Theis, The chemistry of leather manufacture (Reinhold Publishing Corp., New York, N. Y., 1945).

[2] R. B. Hobbs, J. Am. Leather Chem. Assoc. 35, 272 (1940).

[3] Federal Specification for Leather and Leather Products; General Specifications, KK-L-311 (U. S. Government Printing Office, Washington 25, D. C., 1945).

[4] E. R. Theis and E. J. Schaffer, J. Am. Leather Chem. Assoc. 31, 515 (1936).

[5] J. H. Bowes, H. M. Davies, T. A. Pressley, and C. Robinson, J. Intern. Soc. Leather Trades Chem. 31, 236 (1947).

[6] E. R. Theis and R. G. Steinhardt, Jr., J. Am. Leather Chem. Assoc. 37, 433 (1942).

[7] E. R. Theis, J. Am. Leather Chem. Assoc. 37, 499 (1942).

[8] E. R. Theis and W. A. Blum, J. Am. Leather Chem. Assoc. 37, 553 (1942).

[9] W. J. Chater, J. Intern. Soc. Leather Trades Chem. 13, 24, 427 (1929).

[10] W. J. Chater, J. Intern. Soc. Leather Trades Chem. 14, 28, 133 (1930).

[11] W. J. Chater, J. Intern. Soc. Leather Trades Chem. 22, 432 (1938).

[12] J. W. Harnly and W. M. Parker, J. Am. Leather Chem. Assoc. 40, 164 (1945).

[13] E. W. Merry, J. Intern. Soc. Leather Trades Chem. 29, 223 (1945).

[14] W. J. Chater and J. Draper, J. Intern. Soc. Leather Trades Chem. 23, 132 (1939).

[15] E. Wohlisch, Biochem. Z. 24\%, 329 (1932).

[16] C. E. Weir, J. Research NBS 41, 279 (1948) RP 1924.

[17] F. O. Schmitt, J. Am. Leather Chem. Assoc. 39, 430 (1944)

[18] G. C. Nutting and R. Borasky, J. Am. Leather Chem. Assoc. 43, 96 (1948).

[19] F. H. Getman and F. Daniels, Outlines of theoretical chemistry, 5th ed. (John Wiley \& Sons, Inc., New York, N. Y., 1931).
[20] S. Glasstone, K. Laidler, and H. Eyring, The theory of rate processes (McGraw-Hill Book Co., New York, N. Y., 1941).

[21] H. Neurath, J. P. Greenstein, F. W. Putnam, and J. O. Erickson, Chem. Revs. 34, 157 (1944) .

[22] J. H. Highberger, J. Am. Leather Chem. Assoc. 31, 345 (1936).

[23] D. Jordan-Lloyd and W. B. Pleass, Biochem. J. 21, 1352 (1927); 22, 1007 (1928).

[24] J. H. Highberger and F. O'Flaherty, J. Intern. Soc. Leather Trades Chem. 23, 549 (1939).

[25] A. Kuntzel and H. Erdmann, Collegium 824, 630, 639 (1938).

[26] J. R. Kanagy and R. A. Kronstadt, J. Am. Leather Chem. Assoc. 38, 459 (1943).

[27] E. R. Theis. Unpublished results.

[28] C. E. Weir. Unpublished results.

[29] I. C. Somerville, J. Am. Leather Chem. Assoc. 37, 381, 391 (1942).

[30] R. M. Lollar, J. Am. Leather Chem. Assoc. 4\%, 180 (1947).

[31] J. R. Kanagy. Unpublished results.

[32] K. H. Gustavson, J. Intern. Soc. Leather Trades Chem. 31, 176 (1947).

[33] K. H. Gustavson, J. Am. Leather Chem. Assoc. 41, 47 (1946); K. H. Gustavson, Biochem. Z. 311, 347 (1942).

[34] E. R. Theis, J. Biol. Chem. 15\%, 7 (1945).

[35] J. R. Kanagy, Chemistry of collagen, NBS Circular 458 (1947).

[36] A. Kuntzel and K. Doehner, Angew. Chem. 52, 175 (1939).

[37] J. H. Highberger, J. Am. Leather Chem. Assoc. 42, 493 (1947).

[38] J. H. Highberger and H. J. Kersten, J. Am. Leather Chem. Assoc. 33, 16, 289 (1938).

[39] H. Eyring and A. F. Stearn, Chem. Revs. 24, 253 (1939).

Washington, September 20, 1948. 